\title{
OLIVEIRA, Márcia Santos Duarte de; ARAUJO, Gabriel Antunes de. O Português na África Atlântica: Angola, Cabo Verde, Guiné-Bissau e Săo Tomé e Príncipe. São Paulo: Humanitas, 2018. 381p.
}

Ednalvo Apóstolo CAMPOS ${ }^{1}$

O livro O Português na África Atlântica: Angola, Cabo Verde, Guiné-Bissau e São Tomé e Príncipe é composto por uma coletânea de estudos sobre as variedades do português faladas nos países lusófonos, com exceção de Moçambique, em cotejo com as línguas locais. Teve sua primeira edição publicada em 2018 pela Editora Humanitas/USP, em parceria com a Fundação de Apoio à Pesquisa do Estado de São Paulo (FAPESP). Essa edição foi publicada pela mesma editora, em 2019, no formato on-line e está disponível no endereço eletrônico http://www.livrosabertos.sibi.usp.br/portaldelivrosUSP/catalog/ book/421. No ano de 2019, foi publicada a segunda edição pela editora portuguesa Chiado, com patrocínio do Instituto Superior Politécnico do Libolo (ISPTLO), nos formatos impresso e on-line. Essa edição traz nova apresentação e destaca o patrocínio da instituição angolana, com fins de divulgação em áreas educacionais de Angola. $O$ leitor interessado pode adquirir o e-book no endereço https://www.chiadobooks.com/ livraria/o-portugues-na-africa-atlantica.

Os nove ensaios que compõem o livro encontram-se divididos em quatro subseções: Angola, Cabo Verde, Guiné Bissau e São Tomé e Príncipe, além do posfácio. Essas seções são apresentadas por pesquisadores de sete universidades. O caráter acadêmico torna a obra interessante para estudantes, professores e linguistas de modo geral, leitores que se depararão com uma obra riquíssima na apresentação de tópicos linguísticos, discutidos na esteira das teorias do contato linguístico e compreendidos, muitas vezes, sob a noção de continuum de efeitos sobre as variantes oriundas do contato entre as variedades de português e as línguas do tronco linguístico nigero-congolês.

1 Universidade do Estado do Pará (UEPA), Belém, Pará, Brasil; ednalvo.campos@uepa.br; https://orcid.org/0000-0003-4513-7193 
- | O Português na África Atlântica: Angola, Cabo Verde, Guiné-Bissau e São Tomé e Príncipe.

Ao ler os ensaios que integram O português na África Atlântica, é possível reavivar a metáfora do "túnel do tempo" utilizada nos idos das décadas de 1980/90 por Fernando Tarallo (1990) na obra Tempos Linguísticos, ao discutir as origens do português brasileiro. Na obra de Tarallo, o emprego da metáfora se explicava em razão do acesso à história e à estrutura da língua portuguesa, para a qual seria necessário um método de estudo que refletisse a estrutura da língua como sistema vivo e dinâmico capaz de desfazer a separação rigorosa entre diacronia e sincronia. Nesse sentido, o autor lançava um desafio: "picaretas em punhos: vamos cavar!", vislumbrando-se a necessidade de muitos estudos para entender as complexas imbricações de contato linguístico pelas quais passou o português brasileiro.

Os autores da coletânea debruçaram-se sobre as variedades do português faladas na África Atlântica "empunhando suas picaretas" e deram continuidade às escavações do túnel, já bastante percorrido - mas ainda pouco conhecido no que tange às relações de contato em solo brasileiro entre a gramática do português e as das línguas ameríndias e africanas - com as picaretas, agora, escavando "solo africano".

Portanto, perpassam pela obra as questões referentes ao papel ou à participação das línguas do tronco nigero-congolês nas variedades de português faladas em solo africano, tomando como ponto de partida a tradição de mais de 50 anos de estudos linguísticos sobre o português falado no Brasil. Embora as relações de contato linguístico não sejam as mesmas, elas podem, de algum modo, lançar luzes para as questões africanas que começam agora a ser estudadas. A temática é fascinante, pois mergulha na gênese de variedades consideradas parcialmente reestruturadas como português brasileiro (HOLM, 2004) e as variedades africanas emergentes do português em processo de consolidação.

Antes de iniciar a apresentação dos ensaios, ainda é necessário falar da expressão "África Atlântica", presente no título do livro, já que tanto identifica a região de origem das línguas faladas na costa oeste do continente africano, quanto a rota do comércio ilegal de indivíduos escravizados no novo mundo, relacionada às situações de contato linguístico que se estabeleceu entre a língua portuguesa em todos os seus múltiplos processos. No solo africano, a língua portuguesa esteve diretamente em contato com línguas pertencentes ao tronco nigero-congolês, algumas do subgrupo banto, como o quimbundo, quissicongo, etc., outras das famílias linguísticas atlântica e mandê, como wolof, fula, mandinka, bamabarã, etc. Essas últimas serviram de substrato para a formação dos crioulos da Alta Guiné (caboverdiano, kriyol ou guinenese) no arquipélago de Cabo Verde e em Guiné-Bissau e, segundo alguns autores, também para a formação do papiamento na região do Caribe. As línguas das famílias edóide e banto foram substrato das línguas crioulas de São Tomé e Príncipe. 
O ensaio inicial, "Variedades de português angolano e línguas bantas em contato", de Paulo Jefferson P. Araújo, Margarida M. T. Petter e José A. José, alerta sobre o perigo das conclusões precipitadas na empreitada das "escavações", e traz um leque de abordagens teóricas sobre o contato entre línguas às quais se pode lançar mão - com devida atenção e rigor nas análises -, tais como, os modelos substratista (HOLM, 2004, entre outros), evolucionário (MUFWENE, 2004) e psicolinguístico (VAN COETSEM, 2000; MYERSSCOTTON, 2002) e mostram que os modelos mais recorrentemente utilizados nas "escavações" sobre as relações de contato do português com línguas africanas têm sido as abordagens substratistas.

Os autores, no entanto, alegam que muitas análises carecem de um melhor conhecimento das línguas de substrato na fundamentação empírica da natureza do contato entre o português e essas línguas, conhecimento que nem sempre se tem ou é possível ter por falta de informações sobre o contato, por exemplo, em relação às variedades vernaculares do português na África atlântica e os contatos linguísticos que as moldaram ao longo do tempo. Para eles, a escassez de estudos descritivos das línguas de substrato, como as bantas, torna-se um entrave para o real entendimento dos fenômenos de contato estabelecidos entre elas e as variedades de português.

Como exemplo concreto, os autores lembram que o cotejo entre as variedades de português e línguas bantas costuma, normalmente, privilegiar, nas análises, aspectos gramaticais como: a concordância nominal, de número e gênero, a concordância verbal, a colocação pronominal, a negação etc. e citam decalques semânticos tomados como causa direta do contato (como o que ocorre com o verbo nascer - Quando te nasceram? - português do Libolo, p. 29) em que a estrutura argumental do quimbundo costuma ser apontada como a causa do paralelismo. No entanto, os autores observam que nem sempre o "paralelismo pode ser atestado" (p. 30) e dão como exemplo o caso da semelhança entre as estratégias prototípicas de posse nas línguas bantas e a estratégia no português para expressar "posse predicativa" por meio da expressão comitativa "estar com" (estou com a chave do carro, em vez de tenho a chave do carro, p. 30) que levaram Raimundo (1933) a sugerir que o uso de "estar com" em português brasileiro devia-se ao contato com as línguas bantas, acarretando situações problemáticas já que os traços descritos podem estar relacionados a outros fatores. Como contra-argumento, citam o estudo de Heine (1997) que aponta que os domínios conceituais de possessivos e existenciais em diversas línguas seguem um percurso de gramaticalização bastante parecido. Reforçam, assim, que um embasamento empírico e teórico para as correlações de fenômenos morfossintáticos de cunho substratista devem ser feitos com bastante rigor para não incorrer no erro de falsos paralelismos. 
- | O Português na África Atlântica: Angola, Cabo Verde, Guiné-Bissau e São Tomé e Príncipe.

O segundo ensaio "Aspectos histórico-culturais e sociolinguísticos do Libolo: aproximações com o Brasil", de Carlos F. G. Figueiredo, apresenta uma importante resenha histórica com contextualização de diversos fatos e informações acerca do município do Libolo, na Província angolana do Kwanza Sul. São apresentadas noções sobre a constituição sociopolítica do sistema tradicional dos sobados. Além do cenário sociopolítico, o ensaio discute especificidades linguísticas referentes ao léxico e a traços da gramática da variedade de português falada no Libolo e considera que essa variedade, se por um lado, apresenta variações relativamente ao português europeu - língua-alvo no Libolo colonial - por outro, apresenta similaridades tanto com outras variedades de português faladas na África Atlântica, quanto com variedades vernaculares brasileiras. Como exemplo, explora características gerais do sistema pronominal clítico como a próclise e, principalmente, os fenômenos da terceira pessoa clítica, em especial, a recategorização de "Ihe" e o emprego da forma tônica para expressar as funções acusativa e dativa, similares ao que acontece nas variedades brasileiras de português vernaculares (PVB) e, de modo menos categórico, no PB falado.

A partir de documentos históricos, defende que a ligação histórico-linguística entre Angola e Brasil remonta ao período do tráfico humano, no século XV, na área Kambambe/ Kissama/Libolo, argumentando que tanto os traços linguísticos quanto os socioculturais dessa região tenham "viajado para as terras de Vera Cruz" e Caribe, marcando presença tanto na fala quanto nos hábitos e nas tradições culturais brasileiras.

O terceiro ensaio, "Estudos sobre o português falado em Cabo Verde: o estado da arte", de Francisco João Lopes e Márcia S. D. de Oliveira, traz as questões referentes à origem de um dos crioulos da Alta Guiné - o caboverdiano (CCV) -, bem como as questões sociais, políticas e ideológicas que decorrem do status e da "aceitação" dessa língua em solo caboverdiano ${ }^{2}$. Para além disso, menciona questões ligadas à situação sociolinguística de Cabo Verbo: se se trata de uma questão de diglossia ou de bilinguismo. Tais abordagens não são simples e dividem os estudiosos do tema em grupos distintos. Os autores concebem a sociedade caboverdiana como uma comunidade de fala com diversos níveis de bilinguismo e apontam que "Cabo Verde é, por questões de ordem sociopolítica e não linguística, uma nação diglóssica" (p. 109) e consideram que os caboverdianos são falantes bilíngues pois têm o CCV como sua língua materna e falam, com diferentes graus de proficiência, o português de Cabo Verde (PCV).

2 A grafia do adjetivo caboverdiano oscila na obra nas formas caboverdiano, caboverdeano e cabo-verdiano, este último ocorre nas transcrições de autores não brasileiros. Não há, no entanto, nos textos, nenhuma nota sobre a convenção acerca do uso do termo. Talvez pelo fato de o texto tratar de uma resenha de vários autores, o termo "caboverdiano" apresente distintas grafias no ensaio. Optou-se pelo emprego de caboverdiano. 
De modo geral, compreender a situação sociopolítica do português caboverdiano como uma situação de diglossia ou de bilinguismo pressupõe uma questão fundamental e nem sempre bem desenvolvida, pois, para grande parcela da população, o PCV é aprendido em contexto de educação formal escolar, como L2, saindo do contexto de bilinguismo.

O quarto ensaio, "Aquisição do português como L2 em Cabo Verde: alguns aspectos morfossintáticos do contato", de Nélia Alexandre, dialoga com o ensaio anterior no tocante à temática dos aspectos da diglossia e do bilinguismo em Cabo Verde e aponta a situação convergente para a diglossia em vez de bilinguismo. Assim, a referência ao status bilíngue do arquipélago estaria mais adequadamente relacionada a questões ligadas ao campo das políticas linguísticas; já do ponto de vista puramente linguístico, em que o português é aprendido via input primário por meio de aquisição gramatical tardia, quando as crianças já adquiriram a gramática de sua L1, não se trataria mais de contexto de bilinguismo.

No quinto ensaio, "Caboverdiano e Português: cotejando estruturas focalizadas", de Nélia Alexandre e Márcia S. D. de Oliveira, as autoras abordam as estratégias para a focalização de constituinte nominal e propõem que há uma tendência de convergência de estratégias de focalização entre o caboverdiano $\mathrm{CV}^{3}$ e as variedades de português vernacular brasileira (PVB) e o português caboverdiano (PCV). O estudo aborda um conjunto de dados cuja estratégia de focalização se dá de maneira não canônica, sem a presença da cópula, necessária nas estratégias de clivagem/pseudoclivagem, como em "Que que o João comprou?" - fenômeno largamente atestado em variedades do português brasileiro para o qual Kato e Ribeiro (2009) propõem ser o resultado de um processo de gramaticalização que apaga a cópula invariável "é" -, tornando a estrutura clivada sem cópula, mas, ainda assim, uma estrutura bioracional.

O ensaio contra-argumenta o tratamento dado na literatura a essas construções a partir do que Oliveira (2014), entre outras publicações, defende para essas sentenças, consideradas pela autora um tipo "especial" de focalização que se dá, não por apagamento da cópula, mas por reorganização da estratégia de focalização por meio de uma estrutura mono-oracional em que não se atesta cópula (logo, não há apagamento de cópula). O estudo resulta de cotejo entre o caboverdiano e as variedades de português brasileira e caboverdiana, aproximando-as no que diz respeito à estratégia de focalização de ki/que sem cópula. Tal aproximação, defendem as autoras, evidencia uma tendência

3 As siglas não estão padronizadas em todos os ensaios. Ora o crioulo caboverdiano ou apenas caboverdiano tem como sigla o CCV, ora, apenas CV. 
- | O Português na África Atlântica: Angola, Cabo Verde, Guiné-Bissau e São Tomé e Príncipe.

convergente nas estratégias de focalização entre o crioulo caboverdiano e as variedades de português brasileira e caboverdiana cuja estratégia, provavelmente, ocorre por razões de substrato em que falantes de línguas do tronco nigero-congolês, como o wolof, utilizam como estratégia de focalização o deslocamento do elemento focalizado para a periferia esquerda da sentença.

Os ensaios seis e sete voltam-se à descrição da variedade do português falada em Guiné-Bissau (PGB) e trazem aspectos inéditos sobre essa variedade. Os capítulos tecem significativas informações sobre o contexto sociopolítico e sociolinguístico daquele país.

Assim, o ensaio seis, dedicado ao português da Guiné-Bissau, "Contribuições para o estudo da prosódia do português de Guiné Bissau: a entonação do contorno neutro", de Vinícius G. dos Santos e Flaviane Romani F. Svartman, descreve e analisa o padrão entoacional de sentenças declarativas neutras no português de Guiné-Bissau (PGB). O estudo traz seções com informações sobre os aspectos sócio-históricos da GuinéBissau bem como a situação sociolinguística das muitas línguas faladas ali, sobretudo a língua veicular de unidade nacional, o crioulo guineense - Kriyol - assim como o status do português falado na GB, cujo censo de 1991 aponta que somente 9 por cento da população se declarou falante do idioma, sendo a primeira língua de apenas 1 por cento de falantes no país. As comparações dos contornos entoacionais do português de Guiné-Bissau com padrões já descritos para o português brasileiro (PB) e europeu (PE) revelam características entoacionais gerais nessas variedades de português. Além disso, os autores atestam a existência de uma frequente atribuição de acentos tonais a cada palavra fonológica que compõe a sentença no PGB, características que aproximam a altura e a densidade tonal do contorno entoacional com os padrões do PB.

Por fim, os autores argumentam, quanto à associação de acentos frasais às fronteiras de sintagmas fonológicos no PGB, que, embora esse evento tonal seja encontrado no PB e no português do Alentejo (variedade PE), no PGB as propriedades fonológicas são distintas. Atestou-se, ainda, eventos tonais adicionais associados a sílabas pretônicas de palavras fonológicas longas semelhantes aos tons adicionais encontrados em palavras fonológicas do PB.

No segundo ensaio sobre o português de Guiné-Bissau - ensaio sétimo do livro -, "Estudo inicial das perguntas-Q no português de Guiné-Bissau", de Eduardo F. dos Santos e Raquel A. da Silva, os autores chamam a atenção para a possível existência de um continuum linguístico em Guiné-Bissau, dadas as características do contato linguístico entre as diferentes línguas faladas no país como o guineense e o português. O ensaio centra-se no domínio das perguntas-Q diretas, definidas na literatura como 
construções que apresentam palavras do paradigma morfológico dos pronomes-Q construções- $Q$. A descrição do corpus segue a classificação de quatro tipos de construções: (i) interrogativas- $\mathrm{Q}$ com pronome- $\mathrm{Q}$ in situ; (ii) interrogativas- $\mathrm{Q}$ com pronome- $\mathrm{Q}$ deslocado, (iii) interrogativas-Q clivadas e (iv) interrogativas- $Q$ com pronome- $Q$ acompanhado de um "que" e sem cópula ou, como também denominam, perguntasQU fronteadas e seguidas de partícula. Os dados revelam preferência pelo pronome-Q deslocado e baixa ocorrência de sentença com pronome-Q in situ; ocorrências, ainda que baixas, do pronome-Q em estruturas clivadas e, finalmente, ocorrências com pronome-Q seguidas de partícula. Sobre esse último tipo, os autores comparam seu estudo ao de Oliveira e Alexandre, nesse mesmo livro, sobre o português caboverdiano em que se atestam construções do mesmo tipo.

Por fim, os autores apontam que a ocorrência de perguntas-Q fronteadas e seguidas de partícula na variedade de português de Guiné-Bissau não apenas confirma o contraste já apontado entre o português brasileiro e o europeu, mas aproxima a variedade guineense das variedades brasileira e caboverdiana de português, ao mesmo tempo que as afastam do português europeu que não atesta esse tipo de construção, corroborando, mais uma vez, as hipóteses de reestruturação linguística, a partir do contato ocorrido entre essas variedades de português e línguas do tronco nigero-congolês.

Os ensaios oito e nove voltam-se para as variedades de português faladas na República Democrática de São Tome e Príncipe: o português vernacular de São Tomé e Príncipe (PVST) e a variedade de português falada pela comunidade dos Tongas ou "português dos Tongas".

O primeiro deles, o ensaio oito, “Ditongos no português vernacular de São Tomé e Príncipe", de Alfredo Christofoletti e Gabriel A. de Araújo, apresenta o quadro vocálico seguido de uma análise sociolinguística dos ditongos orais decrescentes do PVST. Essa variedade, na posição tônica, apresenta um quadro de sete vogais, mas fora dessa posição, esse número é reduzido. A análise sociolinguística feita avalia os fatores linguísticos e não linguísticos que podem estar atuando no condicionamento de processos de variação e monotongação; alguns deles semelhantes ao que acontece nas variedades de português brasileira e portuguesa, outros, devidos, segundo os autores, a razões do contato com as línguas crioulas - santomense, angolar e lung'ie - faladas nas ilhas que compõem o arquipélago de São Tomé e Príncipe.

O segundo ensaio "O português dos Tongas de São Tomé", de Alan N. Baxter, apresenta um review de outros trabalhos do autor e em parceria com Norma Lopes. Descreve a variedade de português falada pelos Tongas ou "português do tongas" (PT). 
A história dessa variedade, conforme descreve o autor, tem início após a libertação dos escravos em 1876, quando se começa a contratação de trabalhadores de Angola, Moçambique, Cabo Verde, além de outras colônias francesas e inglesas, com o predomínio de angolanos. Os tongas foram serviçais das antigas comunidades agrícolas coloniais e ali permaneceram mesmo após a independência de São Tomé e Príncipe. O ensaio mostra que os tongas manifestaram diferentes graus de manutenção de suas línguas ancestrais, entre as quais o quimbundo e o umbundo, além de falarem a sua própria variedade de português, formando um retrato do que pode ter ocorrido no Brasil em tempos remotos.

Assim, o texto contribui para o debate das origens do português brasileiro, uma vez que apresenta aspectos centrais do contexto sociolinguístico em que o PT se desenvolveu em situação de contato que possibilitou a reestruturação gramatical dessa variedade, tratando-se de um produto clássico, nas palavras do autor, de um processo de transmissão linguística irregular (LUCCHESI; BAXTER; RIBEIRO, 2009) no qual a gramática da L2 contribui substancialmente para a gramática da L1 emergente.

Fechando o volume, a linguista e professora da UNICAMP, Charlotte Galves, apresenta o posfácio do livro "Contato, filiação e gênio das línguas" em um belo ensaio que descortina o fio que conduz toda a obra, trazendo ainda questões teóricas caras ao contato entre línguas já amplamente mencionadas na rica literatura sobre o tema e proposto sob novos olhares, fazendo uma reflexão interessante sobre o "gênio estrutural das línguas" na esteira de Sapir (1921), ao apontar para alguns caminhos a serem trilhados na perspectiva das relações de contato estabelecidas entre o português e as línguas africanas.

Dessa maneira, o espírito engajado de Tarallo "picaretas em punhos: vamos cavar!", utilizado como mote, faz-nos refletir sobre o laboratório fantástico de dados, ideias e princípios e pressupostos do contato linguístico, muitos deles apontados e discutidos em O Português na África Atlântica: Angola, Cabo Verde, Guiné-Bissau e São Tomé e Príncipe, muitos outros com respostas a serem ainda dadas. Os entrelaçamentos teóricometodológicos que unem todos os ensaios presentes na obra certamente trarão algumas respostas ao quebra-cabeças da reestruturação gramatical promovida pelo contato linguístico e, talvez, no futuro, tenhamos novas respostas a partir dessas escavações.

\section{Referências}

ARAUJO, P. J. P.; PETTER, M. T.; JOSÉ, A. J. Variedade de português angolano e línguas bantas em contato. In: OLIVEIRA, M. S. D.; ARAUJO, G. A. O português na África

Atlântica: Angola, Cabo Verde, Guiné Bissau e São Tomé e Príncipe. 2. ed. Lisboa: Chiado Editora, 2019. p. 17-45. 
HEINE, B. Possession. Cognitive Sources, Forces, and Grammaticalization. Cambridge: Cambridge University Press. 1997.

HOLM, J. Languages in contact: the partial restructuring of vernaculars. Cambridge: Cambridge University Press, 2004.

INVERNO, L. C. C. Angola's transition to vernacular portuguese. 2005. Dissertação. (Mestrado em Linguística) - Universidade de Coimbra, Coimbra, 2005.

KATO, M.; RIBEIRO, I. Cleft sentences from Old Portuguese to Modern Portuguese. In: DUFTER, A.; JACOB, D. (ed.). Focus and background in Romance languages. Philadelphia: John Benjamins. 2009. p. 123-154.

LOPES, A. V. C. de M. As línguas de Cabo Verde: uma radiografia sociolinguística. 2011. Tese (Doutorado em Linguística) - Faculdade de Letras, Universidade de Lisboa, Lisboa, 2011.

LUCCHESI, D.; BAXTER, A.; RIBEIRO, I. O português afro-brasileiro. Salvador, Bahia: EDUFBA, 2009.

MUFWENE, S. The Ecology of Lanighlighter' in Atlantic restructured languages:a non cleft construction. PAPIA, Cambridge: Cambridge University Press, v. 24, n. 2, p. 429-449, 2004. Disponível em: http://revistas.fflch.usp.br/papia. Acesso em: 10 jan. 2020.

MYERS-SCOTTON, C. Language Contact: bilingual encounters and grammatical outcomes. Oxford: Oxford University Press, 2002.

OLIVEIRA, M. S. D. DPs/WHs followed by 'highlighter' in Atlantic restructured languages: a non cleft construction. PAPIA, Cambridge: Cambridge University Press, v. 24, n. 2, p. 429-449, 2014. Disponível em: http://revistas.fflch.usp.br/papia. Acesso em: 10 jan. 2020.

RAIMUNDO, J. O elemento afro-negro na língua portuguesa. Rio de Janeiro: Renascença Editora, 1933.

SAPIR, E. Language. New York: Harcourt Brace, 1921.

VAN COETSEM, F. A General and Unified Theory of the Transmission Process in LanguageContact. Heidelberg: Universitätsverlag, C. Winter, 2000. 
- | O Português na África Atlântica: Angola, Cabo Verde, Guiné-Bissau e São Tomé e Príncipe.

COMO CITAR ESTA RESENHA: OLIVEIRA, Márcia Santos Duarte de; ARAUJO, Gabriel Antunes de. O Português na África Atlântica: Angola, Cabo Verde, Guiné-Bissau e São Tomé e Príncipe. São Paulo: Humanitas, 2018. 381p. Resenha feita por Ednalvo Apóstolo Campos. Revista do GEL, v. 17, n. 3, p. 342-351, 2020. Disponível em: https://revistadogel.gel.org.br/

DOI: http://dx.doi.org/10.21165/gel.v17i3.2874

Submetido em: 01/09/2020 | Aceito em: 01/10/2020. 